УДК $811.161 .1 ; 81^{`} 42 ; 81 ` 22$

DOI: $10.17223 / 19986645 / 64 / 8$

\title{
Т.Г. Скребцова
}

\section{СМОТРИТЕ И СЛУШАЙТЕ КАК МАРКЕРЫ ВЛАСТИ И СОЛИДАРНОСТИ}

\begin{abstract}
Анализируются структурные, сематические и прагматические особенности форм повелительного наклонения глаголов зрительного и слухового восприятия, широко используемых в устной речи в качестве так называемых дискурсивных маркеров. Исследование выполнено на материале Национального корпуса русского языка. Основное внимание уделено маркерам «смотрите» и «слушайте», которые по своей функииональной семантике могут быть соотнесены с известными социолингвистическими категориями власти и солидарности.

Ключевые слова: дискурсивный маркер, устная речь, институцииональный дискурс, метакоммуникативная функиия, власть, солидарность.
\end{abstract}

\section{Понятие дискурсивного маркера}

Становление и развитие дискурсивного анализа, когнитивных и функциональных теорий языка в последние десятилетия способствуют росту интереса к особому классу слов и словосочетаний, выполняющих метакоммуникативную функцию в речи, обеспечивая ее организацию и связность. Для их коллективного обозначения был предложен термин дискурсивный маркер (с вариантами дискурсивное слово, дискурсивная частица), характеризующий соответствующие единицы не по традиционному грамматическому, а по функциональному признаку.

Британский лингвист М. Стаббз, автор известного учебника по анализу дискурса, в качестве типичных примеров упоминает well, now, right, anyway, you know, I see, hello, byebye [1. Р. 68]. В первом специальном исследовании, посвященном дискурсивным маркерам в английском языке, в фокус внимания попали такие слова и словосочетания, как oh, well, and, but, or, so, because, now, then, I mean, y'know [2].

В книге [3] в круг дискурсивных слов русского языка включены следующие наречия, частицы, вводные обороты: едва, еле, с трудом, чуть, немного, почти, действительно, в самом деле, на самом деле, в действительности, вообще, в общем, в целом, в принципе, вовсе, совсем, прямо, просто. В более поздней публикации того же коллектива [4] дополнительно рассматриваются следующие единицы: только, лишь, всего, всего лишь, всего-навсего, по крайней мере, по меньшей мере, наоборот, опять, снова, вновь, заново, еще раз, опять же, опять-таки, таки, все же, все-таки, все равно, кстати, впрочем, кроме того, да и, как раз, именно, разве, неужели, наверное, наверняка, авось, небось, пожалуй, что ли, конечно, разумеется, 
естественно. В подходе отечественных авторов отчетливо ощущается влияние грамматической концепции академика В.В. Виноградова, да и сами они отмечают близость рассматриваемых единиц к так называемым «модальным словам» (ср. [5]).

Исследование дискурсивных маркеров расширяется и распространяется на все новые языки по мере накопления корпусов устной речи. Существенный стимул к соответствующим работам на материале русского языка дало создание устного корпуса Национального корпуса русского языка (НКРЯ). В то же время лингвистам до сих пор не удается дать приемлемое определение дискурсивным маркерам как особому феномену языка и очертить его границы. Нетрудно заметить, что списки, предлагаемые различными авторами, заметно различаются. Единственное, пожалуй, с чем соглашаются все исследователи, - это то, что дискурсивные маркеры не образуют группировки по какому бы то ни было грамматическому или семантическому признаку. Основанием для выделения столь разных языковых выражений в одну категорию служит функциональный критерий.

По мнению Д. Шифрин, дискурсивные маркеры служат усилению связности устного дискурса. По существу, они представляют собой инструкцию на предмет того, каким образом следует рассматривать поступающее высказывание, - как ориентированное на говорящего или слушающего, на предшествующий или будущий текст, на информацию или оценку и пр. Дискурсивные маркеры образуют своеобразные «контекстуальные координаты» при порождении и интерпретации высказывания [2]. Отечественные исследователи высказываются в схожем духе, отмечая, что дискурсивные слова «обеспечивают связность текста <..> отражают процесс взаимодействия говорящего и слушающего <...> выражают истинностные и этические оценки, пресуппозиции, мнения, соотносят, сопоставляют и противопоставляют разные утверждения говорящего или говорящих друг с другом, и проч.» [3. С. 7].

Ряд дискурсивных маркеров образовался в процессе лексикализации тех или иных грамматических форм, в частности глагольных (ср. значит, знаете, понимаешь, видите ли, скажем). В толковых словарях русского языка они обычно приводятся при соответствующей вокабуле и сопровождаются пометой «в знач. вводн. слова» или «в знач. межд.».

В настоящей статье рассматриваются лексикализованные формы повелительного наклонения русских глаголов зрительного и слухового восприятия, которые, с нашей точки зрения, можно рассматривать в качестве дискурсивных маркеров. Всех их объединяет функциональная семантика привлечения внимания. Основное внимание уделяется маркерам cмоmpu(me) и слушай(те), однако для большей полноты картины также привлекается материал, связанный с употреблением маркеров посмотри(те), послушай(те), а также видите / видишь, сльиште / сльишиш. Исследование осуществлено на базе НКРЯ, причем преимущественно его устного корпуса. 


\section{Маркер смотри(те)}

Дискурсивный маркер смотрите в значении 'обратите внимание' за последние годы получил чрезвычайно широкое распространение в устной речи, однако толковые словари русского языка пока не успели зафиксировать этот факт. В соответствующих словарных статьях можно найти только омонимичные формы с семантикой либо предупреждения, угрозы («смотрите у меня, не шалите»), либо удивления («смотрите, как вырядился!»), но они нас в данной статье не интересуют. Как маркер привлечения внимания лексикализованная форма смотрите начинает употребляться около двух десятилетий назад (первые фиксации в НКРЯ датируются концом 1990-х гг.) и затем быстро получает закрепление в устной коммуникации. Поскольку это преимущественно институциональная коммуникация, реплика с маркером смотрите представляет собой обращение «на Вы» к единственному адресату. Наиболее типичными являются следующие два вида коммуникативной ситуации.

Во-первых, это общение в сфере сервиса: разговоры клиентов со специалистом (менеджером, администратором, консультантом и т.д.) турфирмы, клиники, санатория, автосалона, фитнес-клуба, салона красоты, агентства недвижимости и пр., где данный маркер практически всегда звучит из уст представителя соответствующей организации. Приведем несколько показательных примеров.

[Антонина, жен] Смотрите / на данный момент / если мы рассматриваем с вами Андорру на четырнадияатое марта на неделю на двух взросльх / то у меня минимальная стоимость выходит от ээ иестидесьти тысяч (Телефонный разговор с менеджером турагентства // Из коллекции НКРЯ. 2015).

[Наталья, жен] Смотрите / расскажу вам немного о нашем комплексе. Aа мы располагаемся на двух уровнях )Звонок в фитнес-клуб // Из коллекции НКРЯ. 2015).

[Алена, жен] Ну вот смотрите / аа я могу вам предложить билеть сектора изэ. Аа они от ээ тысячи рублей до двух с половиной (Заказ по телефону билетов на концерт // Из коллекции НКРЯ. 2015).

Материал НКРЯ часто ограничен рамками единичного высказывания (в устном корпусе) или предложения (в основном и других корпусах). Тем не менее контекст употребления маркера смотрите совершенно понятен: он используется в ответных репликах представителя сервисной организации, следующих за вопросом или просьбой клиента. Реплика с маркером cмоmрите обычно раскрывает подробности той или иной услуги, ее объем и стоимость.

Со структурной точки зрения маркер смотрите, как правило, является стартовым, занимающим начальную позицию в высказывании (слова типа ну, вот, так, входящие в ту же ритмическую группу, не имеют в данном случае самостоятельной ценности). Его семантико-прагматическое содержание в самом общем виде определяется метакоммуникативной функцией, 
направленной на мониторинг контакта (привлечение и удержание внимания), ср. [6. С. 199; 7. С. 43]. Однако то же справедливо и в отношении других маркеров, в частности маркера слушайте, о котором речь ниже. При этом они не взаимозаменяемы. В чем же тогда специфика именно данного маркера?

Характерной особенностью речевой ситуации, в которой употребляется маркер смотрите, является неравноправие сторон в плане компетенции, осведомленности в обсуждаемых вопросах. Данный маркер всегда фигурирует в контекстах, связанных с передачей информации. Вероятно, это обусловлено наличием у глагола «смотреть» производных значений, связанных с умственной деятельностью, ср. смотреть объявления; новую пьесу; больного; смотреть другими глазами на кого-что-л.; смотреть легко на жизнь и т.Д. В силу феномена вторичной активации [8. Р. 68-69] соответствующая семантика проецируется на лексикализованную форму императива смотрите. Употребление маркера смотрите в информирующем речевом акте придает ему дополнительный смысловой оттенок: призыв не только обратить внимание, но и подумать, мысленно прикинуть, взвесить сообщаемые сведения и принять решение. Это объясняет его почти исключительное «присвоение» одной и той же стороной в диалоге, в данном случае - представителями сервисных организаций.

Другая разновидность институциональной коммуникации, в которой также широко представлен рассматриваемый маркер, - это интервью, беседа журналиста с известной личностью. Здесь также наблюдается асимметрия, связанная с употреблением маркера преимущественно приглашенным гостем, ср.:

[Юрий Пивоваров, муж] Причем / смотрите / это ведь очень интересные эпохи - конец восемнадцатого / начало девятнадцатого столетия и середина двадиатого столетия (Юрий Пивоваров. Русская история в зеркале русской мысли. Проект Academia (ГТРК Культура) (2010)).

[Ю.Д. Мостославский, муж] Hy / вот смотрите / значит / вот аa мой отец / он в свое время... (Беседа с директором музея // Из коллекции НКРЯ. 2009).

[И1, муж] Вот смотрите - мь ушли оттуда / пришли американцьь (Беседа с ветераном афганской войны // Из коллекции НКРЯ. 2009).

Структурные и семантико-прагматические особенности употребления маркера в подобных ситуациях в целом схожи с теми, что описаны выше. Однако следует заметить, что институциональное неравноправие здесь не столь очевидно. С одной стороны, роль компетентного и авторитетного участника принадлежит приглашенному лицу, и поэтому маркер смотриmе фигурирует преимущественно в его репликах. С другой стороны, общий мониторинг речевой ситуации в различных ее аспектах (ср. [2. Р. 4850; 6. С. 197-201]) в силу организационных соображений обычно осуществляется журналистом. Распределение этих ролей между участниками (в отличие от рассмотренного выше случая, где обе функции выполняются одной и той же стороной) обусловливает существование некоторого числа 
примеров, где данный маркер произносится не приглашенным лицом, а журналистом, ср.:

[Лев Гулько, муж] Смотрите / значит / наша первая часть с вами закончилась по времени / да / но мы легко можем перейти с темой во вторую часть (Передача «RESET.ПЕРЕЗАГРУЗКА» с Петром Милосердовым (2013)).

[Алина Азарова, жен] Смотрите / значит первый вопрос / Дмитрий Анатольевич / следующего характера (Встреча президента РФ Д. Медведева со студентами факультета журналистики МГУ им. М.В. Ломоносова (2012)).

Разделение указанных функций между приглашенным участником и журналистом фактически означает некоторый баланс между двумя факторами, один из которых - это обладание авторитетом, компетентностью, информированностью (реальной или приписываемой) в обсуждаемых вопроcax, а второй - осуществление общего контроля над коммуникативной инициативой (ср. [9. С. 206-227]). Это делает соответствующую институциональную коммуникацию неоднозначной с точки зрения иерархии власти. Но все же первый фактор в подобных контекстах перевешивает - по-видимому, в силу того что маркер смотрите, как было отмечено выше, сигнализирует призыв не только слушать, но и вникать, следить за мыслью, стараться понять. В речевых жанрах интервью, пресс-конференции и т.п. такой призыв более уместен в устах известной личности, чем журналиста.

Функционирование рассматриваемого маркера не ограничено рамками институционального дискурса, он также встречается, хотя и реже, в бытовом повседневном общении, причем во всех трех вариантах: смотри (обращение «на ты» к единственному адресату), смотрите (обращение «на вы» к множественному адресату) и смотрите (вежливое обращение «на вы» к единственному адресату). При равенстве собеседников с точки зрения социального статуса и ролей употребление данного маркера означает присвоение текущим говорящим более высокого положения с точки зрения владения информацией, оценки и распоряжения ситуацией, ср.:

[Ира, жен] Я просто не отписалась / потому что до последнего в институте не знала / када я даже уйду / поэтому я ждала вот момент / када я пойму. Аа ну / смотри / в принщуипе / я могу там / ну / часам к девяти / к десьти прийти. Аа вот (Планирование встречи // Из коллекции НКРЯ. 2015).

[Ольга, жен] Учитывая / что какая / смотрите / какая она умница. (Разговоры за игрой в карты // Из коллекции НКРЯ. 2009).

/ Ну смотрите / если не хотите / Лиде вторую банку отдайте (Микродиалоги // Из материалов Ульяновского университета. 2007)

Употребление маркера смотрите со значением 'думайте, решайте' в последнем примере фактически является промежуточным случаем между собственно смотри(те) и оборотом смотри(те) сам(u), проявлением диффузности значений [10. С. 77]. Для последнего данная семантика является характерной, ср.: 
[Наташа, жен, 21] У меня дома есть диск / но я не уверена тот ли это Лорка. [Даша, жен, 21] Ну смотри сам / наме дело предложить. [Андрей, муж] Я наверное щас посижу / а потом в гостинииу / спать (Разговор в клубе // Из коллекции НКРЯ. 2006).

Лексикализация форм повелительного наклонения глагола «смотреть», похоже, способствует аналогичному процессу у глагола «посмотреть», хотя «чистых» примеров, где соответствующие формы выступают в качестве дискурсивного маркера, а не производного значения 'обратить внимание', не так много:

[Владимир Путин, муж] Посмотрите / в некоторых странах после проведения Олимпиады там просто пусто совсем (Ежегодная прессконференция В.В. Путина (2014)).

[Григорий Крейдлин, муж] Посмотрите / всегда обращаются с просьбой / «Не мог бы ты прислать фотографию?» (Григорий Крейдлин. Язык тела. Лекции Полит.ру (2011)).

[Ольга, жен] Ну вот посмотри / сколько ты бываешь в неделю здесь? (Разговоры за игрой в карты // Из коллекции НКРЯ. 2009).

Завершая рассмотрение функциональной семантики маркеров смотpu(те) и посмотри(те), уместно вспомнить высказанную И. Свитсер мысль о том, что лексика зрительного восприятия в различных языках имеет выраженную тенденцию развивать значения, относящиеся к области мышления, когниции [11. Р. 38-40] (о том, насколько правомерно такое обобщение, см. [12. С. 92-95]). Примечательно, что лексикализованные словоформы видите / видишь, а также видите ли / видишь ли, как видите / как видишь, сами видите / сам видишь (которые вполне можно квалифицировать как дискурсивные маркеры) также встречаются в контекстах, побуждающих не зрительно, а мысленно обратить внимание, представить себе, задуматься, постараться понять, ср.:

[Миронов, муж] Нет / ну это понятно / но видите / если сильно-то беспокоят / надоедают (Разговор с милиционером о телефонных хулиганах // Из коллекции НКРЯ. 2009).

[№ 2, жен, 22] Но / видишь / Стас говорит / что на проект вряд ли придет девушка / которая ему понравится (Беседа участников реалитишоу «Дом-2», ТНТ // практиканты, 2005).

А ему, трактористу, видите ли, лень было из кабины вылезать, лень было ворота отпирать (Круши, чтобы не думать (2003) // Криминальная хроника. 2003.07.24).

[Лида, Наталья Тенякова, жен, 22, 1944] Но / как видишь / мне это не принесло счастья (Георгий Натансон, Александр Володин. Старшая сестpa, $\mathrm{\kappa} / \phi(1966))$.

Сами видите, что развитие техники и науки шло так стремительно в бурном XX веке и веке нынешнем, что даже «завтра» непредсказуемо [Аджубей Р.Н. О науке, о жизни и о себе // Наука и жизнь. 2009). 


\section{Маркер слушай(те)}

Если дискурсивный маркер смотри(те) несет в себе семантику неравноправия, связанную с более высоким уровнем компетенции того участника, который его употребляет, то слушай(те), напротив, можно обозначить как маркер равенства, поскольку не существует какой-либо выраженной асимметрии, связанной с его использованием. При отсутствии разницы в социальном статусе и / или роли, слушай либо слушайте (неважно, при обращении к единственному или множественному адресату) может быть произнесено любым участником в качестве призыва к вниманию.

Для маркера слушай(те), так же как и для смотри(те), характерна стартовая позиция в высказывании. В реактивных репликах он выполняет функцию привлечения внимания, ср.:

[В квартире Фандорина] [по телефону] [Фандорин, Олег Меньшиков, муж, 45, 1960] Слушайте / поступайте как хотите / вы мешаете мне дедуктировать (Филипп Янковский, Борис Акунин. Статский советник, к/ф (2005)).

[Первый, Сергей Маковецкий, муж, 49, 1958] У меня была жена. [Восьмой, Михаил Ефремов, муж, 44, 1963] Слушайте / давайте про жен потом. У меня три было жены (Никита Михалков и др. Двенадцать, к/ф (2007)).

[Виктория, жен] Они в отеле были / да. [Полина, жен] Слушай / еще это / еще ниче. [Виктория, жен] Я говорю / посмотри / что она... ну / в отеле они такие [Разговор подруг // Из коллекции НКРЯ. 2010).

Однако данный маркер может использоваться не только в реактивной, но и в начальной реплике речевого обмена (в том смысле, как данный термин понимается в трудах бирмингемской школы анализа дискурса, см., например [13]). В таком случае он одновременно служит для привлечения внимания и сигнализирует введение новой темы, ср.:

[Алексей, муж] Не знаю пока. [Александра Григорьевна, жен] Слушай/ че-то ветер такой холодный подул. [Михаил, муж] Ну да / тучки вон пошли / ну обещали во второй половине дня дождь (Домашний разговор // Из коллекции НКРЯ. 2008).

[Иван, муж, 18] Так что еще осталось? Слушайте про маршрутку мы совсем забыли. Нам же еще туда как-то добираться надо / не пешком же! (О подготовке к дню рождения // Из материалов Ульяновского университета. 2006).

Любопытный пример присутствия в одной реплике двух маркеров с разными функциями демонстрирует следующий пример, где слушай используется в реактивном высказывании для привлечения внимания, а слушайте служит сигналом смены темы, открывающим новый речевой обмен:

[На стройке] [Артур, Артур Смольянинов, муж, 23, 1983] Слушай / подожди. Слушайте / а че режиссер молчит? Ни «стоп» / ни «снято» / команд никаких! (Резо Гигинейшвили. Жара, к/ф (2006)).

В условиях институционального или прочего неравенства использование маркера слушайте участником с более низким статусом и / или соци- 
альной ролью не только служит для привлечения внимания, но и фактически означает заявку на равенство в том, что касается права быть услышанным и понятым. Например:

[Управляющий, Алексей Марченко, муж] Если получится / если не отвлекаться / не петь... [Женщина в кимоно, Лия Ахеджакова, жен, 68, 1938] Слушайте / я же показания даю. Я вон свидетель (Кирилл Серебренников и др. Изображая жертву, к/ф (2006)).

Особенности функционирования маркеров послушай и послушайте в целом аналогичны описанным выше типовым употреблениям маркеров слушай и слушайте, ср.:

[Нина, Анна Михалкова, жен, 32, 1974] Что ты ... что ты начинаешь... [Никита, Дмитрий Шевченко, муж, 42, 1964] Послушай / не шуми. Я ж не устраиваю тебе сиен (Авдотья Смирнова. Связь, к/ф (2006)).

[Анатолий Чубайс, муж] Нy / послушайте / это же был девяносто четвертый год (Анатолий Чубайс в программе «Познер» (Первый канал) (2008)).

[Джейн Кэллахан, Джулия Ормонд, жен] Но прошу вас / давайте не будем говорить щас об этом. Послушайте / у вас замечательная библиотека / генерал. [Генерал Радлов, Алексей Петренко, муж, 60, 1938] Потише. (Никита Михалков, Рустам Ибрагимбеков. Сибирский цирюльник, к/ф (1998)).

[Ольга, жен, 30] Послушайте / вы понимаете / что мне некогда болеть (В кабинете у врача // Из коллекции НКРЯ. 2006).

Возвращаясь к маркеру слушайте, следует отметить, что он вошел в русский язык гораздо раньше маркера смотрите; в основном корпусе НКРЯ есть цитата начала XX в. (вполне вероятно, что это не самый ранний пример):

Музыка снова играет, и в ее плавные танщуюшие звуки вмешиваются отрывки странного, пугающего разговора: - Слушайте, кондуктор, отчего не идет поезд? Юрасов замедляет шаги и вслушивается (Л.Н. Андреев. Bop (1904)).

Несмотря на то, что подобное употребление существует уже более сотни лет, оно не обнаруживает столь высокую степень десемантизации, как у маркера смотрите. Это связано, по-видимому, с тем, что развитие значения от зрения (визуального восприятия) до мышления (восприятия информации) предполагает большее «расстояние», чем от восприятия на слух до внимания к словам собеседника, и потому особенно обращает на себя внимание.

Заметим, что маркеры сльшишиь, сльшише, хотя и встречаются реже, чем слушай(те), тоже служат для привлечения и удержания внимания, подчеркивания важности сообщения, ср.:

[Саша, муж, 22] Да / сльшишь я сегодня присел двести десять на четыре / двести пятнадиать на три / потом двести двадияать на два / вот / а на соревнованиях двести десять не присел (Телефонные разговоры студентов // Из коллекции Ульяновского университета. 2008-2009). 
[по телефону] [Программный директор, Андрей Шарков, муж, 48, 1958] Але / але / Емельянова / сейчас же / сльците / сейчас же прекратите это! (Оксана Бычкова, Нана Гринштейн. ПитерFМ, к/ф (2006)).

\section{Выводы}

В последние годы в русскую речь в качестве нового дискурсивного маркера стремительно вошли формы повелительного наклонения глагола смотреть (смотри, смотрите). Можно предположить, что этому способствовали существовавшие с более ранних времен маркеры, образованные от глаголов слушать, видеть, сльишать. Тем самым сложилась законченная система дискурсивных маркеров, производных от основных пар глаголов зрительного и слухового восприятия (доминант соответствующих лексико-семантических полей) и объединенных метакоммуникативной функцией поддержания контакта, привлечения и удержания внимания.

Между данными маркерами существуют различия, связанные как с семантико-прагматическими, так и со структурными характеристиками. Так, маркеры смотри(те) и видите / видишь акцентируют аспекты, связанные с пониманием сообщения, а слушай(те) и слышите / слышишь делают упор на внимание и готовность его воспринять (тем самым подтверждая мнение И. Свитсер по поводу семантической деривации лексики чувственного восприятия). С точки зрения структуры высказывания, смотрите и слушайте являются преимущественно стартовыми маркерами, а видите и слышите не закреплены строго за определенной позицией.

Есть также важный прагматический фактор, обеспечивающий дифференцированное употребление маркеров в зависимости от характера коммуникативной ситуации и статусных отношений между участниками. Маркер смотрите (и видите тоже, хотя, как кажется, в меньшей степени) используется участником с более высоким статусом компетентности и авторитетности. Это участник, который в рамках текущего общения наделен своеобразной властью (властью знаний, информации) над собеседником. В отличие от него, маркер слушайте (и слышите) предполагает равные отношения или, по крайней мере, восприятие их в качестве таковых. Сказанное позволяет провести аналогию с социолингвистическими понятиями власти и солидарности, впервые выделенными в статье [14], а позднее занявшими центральное место в исследованиях, посвященных межгрупповым и межличностным отношениям. Смотрите в таком случае можно считать маркером власти, а слушайте - маркером солидарности.

\section{Литература}

1. Stubbs M. Discourse Analysis: The Sociolinguistic Analysis of Natural Language. Oxford : Blackwell Publishers, 1983. $274 \mathrm{p}$.

2. Schiffrin D. Discourse markers. Cambridge : Cambridge University Press, 1987. 364 p.

3. Баранов А.Н., Плунгян В.А., Рахилина Е.В. и др. Путеводитель по дискурсивным словам русского языка. М. : Помовский и партнеры, 1993. 206 с. 
4. Дискурсивные слова русского языка: опыт контекстно-семантического описания / под ред. К. Киселевой, Д. Пайара. М. : Метатекст, 1998. 447 с.

5. Виноградов В.В. Русский язык : Грамматическое учение о слове. М. ; Л. : Учпедгиз, 1947. $784 \mathrm{c}$.

6. Макаров М.Л. Основы теории дискурса. М. : Гнозис, 2003. 280 с.

7. Богданова-Бегларян Н.В. Функционирование некоторых прагматем русской устной речи в коммуникации представителей разных социальных групп // Вестник Пермского университета. Российская и зарубежная филология. 2016. Вып. 2. С. 38-49.

8. Langacker R.W. A view of linguistic semantics // Topic in Cognitive Linguistics / ed. by B. Rudzka-Ostyn. Amsterdam ; Philadelphia : John Benjamins, 1988. P. 49-90.

9. Иссерс О.С. Коммуникативные стратегии и тактики русской речи. 3-е изд. М. : УPCC, 2003. $284 \mathrm{c}$.

10. Шмелев Д.Н. Проблемы семантического анализа лексики. М. : Наука, 1973. 278 с.

11. Sweetser E. From Etymology to Pragmatics: Metaphorical and Cultural Aspects of Semantic Structure. Cambridge : Cambridge University press, 1990. 174 p.

12. Скребцова Т.Г. Когнитивная лингвистика: классические теории, новые подходы. М. : Издательский дом ЯСК, 2018. 392 с.

13. Advances in Spoken Discourse Analysis / ed. by M. Coulthard. London ; New York : Routledge, 1992. 272 p.

14. Brown R., Gilman A. The pronouns of power and solidarity // Style in Language. Cambridge : MIT Press, 1960. P. 253-276.

\section{The Russian Verb Forms Smotrite and Slushayte as Markers of Power and Solidarity}

Vestnik Tomskogo gosudarstvennogo universiteta. Filologiya - Tomsk State University Journal of Philology. 2020. 64. 109-119. DOI: 10.17223/19986645/64/8

Tatiana G. Skrebtsova, Saint Petersburg State University (Saint Petersburg, Russian Federation).E-mail: t.skrebtsova@spbu.ru

Keywords: discourse marker, spoken discourse, institutional discourse, metacommunicative function, power, solidarity.

The study deals with the way imperative forms of Russian visual and auditory perception verbs function as discourse markers in contemporary spoken Russian. The data is drawn from the Russian National Corpus. The article focuses on the forms smotri(te) ('look') and slushay(te) ('listen') (both formal and intimate), but also extends to analogous forms of other verbs of seeing and hearing that can occur as discourse markers, such as vidite, slyshite, poslushayte, etc. In spoken discourse, all of them perform a metacommunicative function of attracting attention and keeping the interlocutor involved, but there are important differences concerning their position in the utterance, semantic and pragmatic features. Both smotrite and slushayte are normally placed at the beginning of a clause, which may not be the case with other markers. But while sharing the same position, their functional semantics differs quite noticeably. Smotrite is commonly used in institutional communication, whereas slushayte is more typical of everyday informal conversations. A rough-and-ready analysis reveals that smotrite occurs mainly in informative speech acts. It is produced by speakers who are considered more knowledgeable and competent, their role in communication being to provide information, make explanations, put forward ideas, express opinions. As it stands, such participants are assigned a higher status linked with the notion of power (power of information). The marker slushayte, on the contrary, signals equality and is associated with the opposite end of the wellknown power-solidarity scale. Its central role is calling for attention, and in some contexts it can also mark the introduction of a new topic. These findings support Eve Sweetser's claim concerning the semantic linkups between vision and intellection, on the one hand, and hearing and receptivity, on the other. The lexicalization process by which the imperative forms in question became discourse markers did not occur at the same time. Thus, while there is evidence that slushayte, slyshite, vidite have been used as discourse markers for many decades, this is not 
the case with smotrite. The latter did not emerge until quite recently, the earliest occurrences in the corpus dating back to the late 1990s. It may be claimed that it was the systemic need that underlay its coinage. With smotrite added to the above units, the system of the Russian verbs of seeing and hearing, as well as the system of corresponding discourse markers, has become complete and well-integrated.

\section{References}

1. Stubbs, M. (1983) Discourse Analysis: The Sociolinguistic Analysis of Natural Language. Oxford: Blackwell Publishers.

2. Schiffrin, D. (1987) Discourse Markers. Cambridge: Cambridge University Press.

3. Baranov, A.N. et al. (1993) Putevoditel' po diskursivnym slovam russkogo yazyka [Guide to Russian Discursive Words]. Moscow: Pomovskiy i partnery.

4. Kiseleva, K. \& Payar, D. (eds) (1998) Diskursivnye slova russkogo yazyka: opyt kontekstno-semanticheskogo opisaniya [Russian Discursive Words: The Experience of Contextual-Semantic Description]. Moscow: Metatekst.

5. Vinogradov, V.V. (1947) Russkiy yazyk. Grammaticheskoe uchenie o slove [The Russian Language. A Grammatical Doctrine of the Word]. Moscow; Leningrad: Uchpedgiz.

6. Makarov, M.L. (2003) Osnovy teorii diskursa [Fundamentals of the Theory of Discourse]. Moscow: Gnozis.

7. Bogdanova-Beglaryan, N.V. (2016) Pragmatic Items Functions in Russian Everyday Speech of Different Social Groups. Vestnik Permskogo universiteta. Rossiyskaya i zarubezhnaya filologiya - Perm University Herald. Russian and Foreign Philology. 2. pp. 38-49. (In Russian).

8. Langacker, R.W. (1988) A view of linguistic semantics. Inn: Rudzka-Ostyn, B. (ed.) Topic in Cognitive Linguistics. Amsterdam; Philadelphia: John Benjamins. pp. 49-90.

9. Issers, O.S. (2003) Kommunikativnye strategii i taktiki russkoy rechi [Communicative Strategies and Tactics of Russian Speech]. 3rd ed. Moscow: URSS.

10. Shmelev, D.N. (1973) Problemy semanticheskogo analiza leksiki [Problems of Semantic Analysis of Lexis]. Moscow: Nauka.

11. Sweetser, E. (1990) From Etymology to Pragmatics: Metaphorical and Cultural Aspects of Semantic Structure. Cambridge: Cambridge University Press.

12. Skrebtsova, T.G. (2018) Kognitivnaya lingvistika: klassicheskie teorii, novye podkho$d y$ [Cognitive Linguistics: Classical Theories, New Approaches]. Moscow: Izdatel'skiy dom YaSK.

13. Coulthard, M. (ed.) (1992) Advances in Spoken Discourse Analysis. London; New York: Routledge.

14. Brown, R. \& Gilman, A. (1960) The pronouns of power and solidarity. In: Sebeok, T. (ed.) Style in Language. Cambridge: MIT Press. pp. 253-276. 